\title{
Formação inicial de professores e a escrita reflexiva
}

\author{
Initial teacher training and reflective writing
}

\section{Formación inicial de profesores y escritura reflexiva}

\author{
Vilma Nunes da Silva Fonseca' \\ https://orcid.org/0000-0003-38|3-1797
}

\begin{abstract}
Resumo: Neste artigo, discutimos como se dá o processo de reflexão de estagiários sobre a prática docente a partir da constituição de saberes adquiridos pelo aluno-mestre nos contextos escolar e acadêmico. Para isso, buscamos evidenciar na perspectiva de Smyth (1991), o percurso dos movimentos reflexivos realizados pelo futuro professor durante a produção de textos escritos no Estágio Supervisionado Curricular. Os fragmentos textuais analisados foram extraídos de relatórios de estágio supervisionado e de diários de campo, disponibilizados para pesquisa no Centro Interdisciplinar da Memória dos Estágios Supervisionados, da Universidade Federal do Tocantins. Essa incursão teórico-analítica de natureza documental aponta que os acadêmicos assumem uma postura reflexiva à medida que registram percepções que integram o conjunto de informações que contextualizam o contato com a escola, com os professores, com os alunos da Educação Básica e com o ambiente de ensino na universidade.
\end{abstract}

Palavras-chave: Estágio Supervisionado Curricular. Formação inicial do professor. Escrita reflexiva.

\begin{abstract}
In this article, we discuss how the process of reflecting trainees on teaching practice occurs from the constitution of knowledge acquired by the master student in the school and academic contexts. For this, we seek to show, in Smyth's (199I) perspective, the path of reflective movements carried out by the future teacher during the production of texts written in the Supervised Curricular Internship. The textual fragments analyzed were extracted from supervised internship reports and field diaries, made available for research at the Centro Interdisciplinar da Memória dos Estágios Supervisionados, at the Universidade Federal do Tocantins. This theoretical-analytical incursion of documentary nature points out that academics assume a reflexive posture as they record perceptions that integrate the set of information that contextualizes the contact with the school, with teachers, with Basic Education students and with the teaching environment teaching at the university.

Keywords: Supervised Curricular Internship. Initial teacher training. Reflective writing.
\end{abstract}

Resumen: En este artículo se discute cómo el proceso de reflexión de los aprendices sobre la práctica docente se da a partir de la constitución de los conocimientos adquiridos por el estudiante de maestría en el contexto escolar y académico. Para ello, buscamos mostrar, en la perspectiva de Smyth (1991), la trayectoria de los movimientos reflexivos realizados por el futuro docente durante la producción de textos redactados en el Internado Curricular Supervisado. Los fragmentos textuales analizados fueron extraídos de informes de pasantías supervisadas y diarios de campo, disponibles para investigación en el Centro Interdisciplinar da Memória dos Estágios Supervisionados de la Universidade Federal do Tocantins. Esta incursión teórico-analítica de carácter

'Doutora em Letras (Ensino de Língua e Literatura), professora do Curso de Letras e do Mestrado Profissional em Letras - Rede Nacional (ProfLetras) do Câmpus de Araguaína, na Universidade Federal do Tocantins. E-mail: vilmanunes@uft.edu.br 
documental señala que los académicos asumen una postura reflexiva al registrar percepciones que integran el conjunto de información que contextualiza el contacto con la escuela, con los docentes, con los alumnos de Educación Básica y con el entorno docente docencia en la universidad.

Palabras-clave: Pasantía curricular supervisada. Formación inicial del professorado. Escritura reflexiva.

\section{Introdução}

O Estágio Supervisionado Curricular (ESC) é uma etapa fundamental na formação dos professores nas licenciaturas, pois compreende um espaço de interdiscursividades e de aprendizagens, no qual o aluno-mestre (AM) pode refletir mais detidamente sobre a relação entre teoria e a prática, não só em decorrência de seu contato direto com a sala de aula da Educação Básica (EB), mas também em consequência das trocas dialógicas experienciadas que certamente são efetivadas nos contextos universidade e escola.

No contexto do ESC, os acadêmicos (neste texto, também utilizamos o vocativo 'professores em formação inicial', 'estagiários', 'aluno-mestre' ou, apenas, AM para nos referirmos aos alunos de ensino superior) são orientados a produzir textos acadêmicos para registrar suas experiências em sala de aula, tais como: relatórios, portfólios, relatos reflexivos e diários de campo.

Neste artigo, apresentamos uma discussão sobre como o aluno-mestre se inscreve na e pela escrita de textos formativos e assume uma postura reflexiva (a partir de sua experiência como professor em formação inicial) da realidade da sala de aula e do trabalho didático-pedagógico desenvolvido por professores da EB que supervisionam o ESC. Para isso, recorremos à análise de fragmentos textuais extraídos de dois gêneros acadêmicos comumente produzidos por estagiários, o relatório de estágio supervisionado (RES) e o diário de campo (DC), uma vez que se trata de textos que potencializam a reflexão do aluno-mestre sobre a prática docente, sendo, aqui, considerados gêneros catalisadores (SIGNORINI, 2006).

Acreditamos que, assim como a escrita do RES, a produção textual diarista do professor em sala de aula pode extrapolar a expectativa da elaboração de um texto meramente narrativo, podendo possibilitar ao acadêmico o discernimento acerca das questões que dizem respeito ao fazer professoral, vindo a problematizá-lo, fato que explicita a relevância deste estudo.

Os DC e os RES analisados nesta investigação foram elaborados por estagiários durante as ofertas das disciplinas Investigação da Prática Pedagógica e Estágio Supervisionado em Língua Portuguesa: Língua e Literatura I, II, III e IV, na Licenciatura em Letras (LL), da Universidade Federal do Tocantins (UFT). Tais textos apresentam os relatos de experiências docentes de estagiários e refletem, numa visão longitudinal, o desenvolvimento da aprendizagem desses acadêmicos com um aprofundamento do nível de consciência acerca do processo formativo no ESC.

Para a realização deste estudo de abordagem qualitativa e natureza documental foram 
realizadas consultas ao acervo do Centro Interdisciplinar da Memória dos Estágios Supervisionados (CIMES), setor de arquivamento de material de pesquisa que possui a salvaguarda dos RES de diferentes cursos de licenciatura da instituição de ensino superior em questão. Os DC compreendem um dos anexos dos RES, portanto, o acesso aos últimos viabilizou o contato com os primeiros. Os fragmentos textuais analisados estão rotulados de acordo com as seguintes informações que aparecem ao final de cada quadro: a letra inicial do nome do aluno-mestre, a etiqueta DC ou RES, o tipo de estágio (I, II, III, IV) e a data da escrita.

Não raro, os DC e os RES evidenciam práticas e comportamento de docentes no exercício de suas profissões, como também focalizam o próprio AM em seu aprendizado nas escolas-campo de estágio. Nessa perspectiva, interessa-nos discutir como se dá, nesses textos, o processo de reflexão dos estagiários sobre a formação docente a partir da constituição de saberes adquiridos pelo AM nos contextos escolar e acadêmico.

Para realizar essa incursão teórico-analítica, no tocante à formação de professores e estágio supervisionado curricular, destacamos as contribuições de Zeichner (1998, 2008), Smyth (199I), García (1989; 1995), Perrenoud (2002) e Freire (1996).

Visando atender ao objetivo delineado, este texto está organizado de acordo com as seguintes seções e subseções (excetuando a Introdução, as Considerações finais e as Referências): "Práticas de linguagem no contexto do estágio supervisionado curricular" - "Sobre a produção de diários de campo" e "Sobre a produção de relatórios de estágio supervisionado"; "Formação do professor pelo viés da reflexividade".

\section{Práticas de linguagem no contexto do estágio supervisionado curricular}

A escrita é uma prática social e cotidiana. Na profissão do professor, a escrita não é apenas uma ferramenta, ela é o produto e o processo pelo qual desencadeia toda a realização do seu trabalho. No ambiente universitário, durante o processo de formação inicial, o futuro professor é instigado a produzir diferentes gêneros acadêmicos, dos quais destacamos a elaboração do relatório de estágio supervisionado e do diário de campo.

$\mathrm{Na}$ academia, os textos são normatizados, institucionalizados em obediência às especificidades que cada gênero exige. Em algumas situações, os textos se tornam "engessados", em relação ao formato, e seus autores ficam presos a uma eterna busca pela impessoalidade no discurso. Nessas circunstâncias, perdem-se aos poucos as singularidades das subjetividades da escrita comum.

Fiad e Silva (2009) apontam para uma recente reorientação das práticas de escrita na academia que passam a reconhecer e "estimular uma produção de caráter mais narrativo e subjetivo, na qual a maior referência é o próprio autor, sua percepção dos fatos, suas experiências e formas de significação" 
(FIAD; SILVA, 2009, p. 123). Mesmo assim, escrever na universidade requer, além das competências linguística e textual, o conhecimento dos usos da língua para os fins da atividade de linguagem empreendida.

Silva e Fajardo-Turbin (2012) acentuam que com vistas a atender aos requisitos avaliativos exigidos na formação inicial, os alunos-mestres compõem ao longo da graduação um conjunto de gêneros escritos. Tais gêneros da esfera acadêmica, representados por diferentes formas genéricas, como aquelas que foram suscitadas no início desta seção (RES e DC), são amplamente explorados pelos professores formadores no desenvolvimento de uma didática da escrita.

\section{Sobre a produção de diários de campo}

No contexto acadêmico, em termos de aplicação geral, a produção de DC é uma técnica de documentação de pesquisa bastante utilizada em estudos qualitativos. Além do mais, também compreende "uma antiga prática de letramento bem consolidada em nossas culturas" (BORTONIRICARDO, 2008, p. 47).

A orientação consensual entre os pesquisadores é que o contato com o campo de pesquisa seja registrado em notas ou anotações imediatamente a finalização das atividades previstas. $O$ distanciamento temporal, ainda que em curto intervalo, pode modificar um ponto de vista e "acabar introduzindo certa artificialidade na relação com os parceiros de interação no campo" (FLICK, 2009, p. 267).

Nas pesquisas em salas de aula, a elaboração de diários é cada vez mais estimulada, pois concerne numa prática de registro de dados própria do pesquisador qualitativo. Para o professorpesquisador (formação inicial ou continuada), a escrita de DC desenvolve o letramento do professor e fomenta o crescimento individual através da reflexão sobre o exercício docente.

De acordo com Bortoni-Ricardo (2008, p. 46), a escrita de diários é uma "prática muito familiar aos professores" e, ainda segundo a autora, "é possível fazer anotações entre uma atividade e outra" na sala de aula, ou seja, intercalar o registro em diários com as atividades pedagógicas do professor.

Desse modo, o DC reflete um pedaço de realidade que compõe a realidade complexa do trabalho do professor, ambas, móveis e fluídas. Trata-se de um texto embebido pela percepção de quem o escreve que, por sua vez, exerce o critério de seletividade dos acontecimentos ao compor suas anotações. Através dos DC são reveladas, além de outros temas relevantes, as comparações das realidades geradas pela troca de saberes socioculturais nas relações interpessoais e na negociação de papéis entre professores e alunos no ESC.

Nessa perspectiva, o DC é um instrumento que fortalece o crescimento profissional do professor através do aprendizado pela reflexão de suas práticas pedagógicas. A produção diarista ajuda 
a promover a prática de escrita reflexiva no dia a dia da profissão do professor e o auxilia a interpretar o contexto da sua sala, como também a "construir sua teoria", avaliar sua "metodologia já posta em prática, ou propostas para uma atividade futura" (BORTONI-RICARDO, 2008, p. 47).

\section{Sobre a produção de relatórios de estágio supervisionado}

O RES está situado dentro de um "sistema de gêneros" (BAZERMAN, 20II), no qual os textos são produzidos e veiculados na esfera dos gêneros acadêmicos. O RES é definido como sendo um texto que pode ser caracterizado como "instrumento mediador da construção de uma prática de reflexão crítica sobre a ação profissional, no cotidiano do trabalho do professor" (SILVA, 20I3, p. 3I).

No contexto da licenciatura alvo da discussão, o RES pode ser compreendido como um macro gênero textual, pois a ele somam-se outras formas genéricas que podem ser identificadas na materialidade textual. No cenário investigado, o relato reflexivo é um gênero comumente solicitado pelos professores formadores da LL (Habilitação em Língua Inglesa), geralmente aparece como uma seção nos RES. Outro gênero que pode compor o RES é o DC. No caso, esse último, alimenta o RES com as informações geradas para a elaboração do diagnóstico da escola e da sala de aula.

O RES pode conter outros exemplares textuais de diferentes gêneros em sua composição. Alguns desses gêneros podem aparecer no corpo do texto ou na seção dos anexos, tais como: as atividades de ensino realizadas nas aulas de LP; as produções textuais dos alunos da EB; os planejamentos de aula; os documentos exigidos pela instituição formadora para a realização do ESC ou outros.

No processo de elaboração dos RES, no ESC, os acadêmicos tendem a reformular os seus textos diante da falta de familiaridade com a escrita e com o gênero RES, muitas vezes são produzidas várias versões. Em alguns casos, os textos são reescritos pelos estagiários visando atender, além das exigências em relação à formatação, às orientações do professor-formador por se tratar de uma atividade avaliativa.

De acordo com Silva e Fajardo-Turbin (20I2), "provavelmente, a produção desses relatórios se configura como a primeira experiência de uso da escrita reflexiva sobre a própria prática profissional" (SILVA; FAJARDO-TURBIN, 20I2, p. 18). Na LL, a disciplina de ESC é o componente curricular no qual o AM vivencia esse contato mais intenso com a escrita reflexiva a partir das suas experiências docentes através da produção dos RES.

Narrar e descrever são atividades linguísticas encontradas em diferentes gêneros, é comum elas constituírem os RES, pois se trata de práticas de escrita herdadas de uma tradição discursivocultural secular manifestada em diversos contextos da vida. Assim sendo, ressaltamos a discussão teórica sobre gênero na pesquisa de Fiad e Silva (2009) na qual as autoras, ao discorrerem sobre o 
gênero relato de estágio, abordam o fato de que "os relatos trazem, em sua elaboração, a história de outros gêneros acadêmicos e não acadêmicos que fazem parte desse universo comunicacional dos estagiários" (FIAD; SILVA, 2009, p. 125).

Comungamos com a opinião das pesquisadoras e adotamos a mesma visão crítica considerando essa constituição genérica dos RES da LL. Além dos RES carregarem em si a marca histórica da existência de outros gêneros (acadêmicos e não acadêmicos), esses textos estão situados numa linha limítrofe do portfólio, dada a semelhança devido à "compilação de fichas de acompanhamento, atividades didáticas, fotografias, dentre outros documentos comprobatórios da experiência vivenciada" (SILVA, 2013, p. 177).

No entanto, as narrações e descrições devem ser acompanhadas de comentários analíticos que versem sobre a realidade de ensino na escola e na sala de aula observadas. $O$ aluno-mestre pode fundamentar a sua escrita com as leituras teóricas apresentadas no contexto das aulas de orientação e balizadas pelo arcabouço teórico adquirido ao longo da formação. Silva (20I3) ressalta que a ocorrência de uma

Subtilização da escrita reflexiva se daria quando o aluno-mestre, minimamente, não associa a experiência vivenciada, nas escolas de educação básica, ao conhecimento teórico trabalhado na própria licenciatura, configurando o referido gênero [RES] num texto predominantemente narrativo e descritivo, informado, quando muito, por impressões diversas (SILVA, 2013, p. 176).

Silva (2013) expõe a sua preocupação quanto à valorização da escrita reflexiva dos RES quando o estagiário não consegue estabelecer vínculos entre os saberes acadêmicos, construídos no curso formador, e os saberes relacionados ao aprendizado da vivência no campo de estágio. O RES é um "gênero catalisador" (SIGNORINI, 2006), pois através da sua escrita ○ AM realiza o movimento dialógico de pensar no seu agir e agir em função dessa reflexão. O RES mobiliza uma mudança interior no aluno-mestre, no professor regente e no professor formador à medida que provoca a reflexão desses profissionais sobre as suas práticas docentes.

\section{Formação do professor pelo viés da reflexividade}

García (1989, p. 30) define "a formação de professores como um campo de conhecimento, pesquisa e de propostas teóricas e práticas" que envolve os professores em formação inicial ou em serviço. Ainda segundo o autor, nesses processos, os docentes são envolvidos

Em experiências de aprendizagem através das quais adquirem ou aprimoram os seus conhecimentos, habilidades e disposições, permitindo-lhes intervir profissionalmente no desenvolvimento do ensino, do currículo e da escola, com o objetivo de melhorar 
a qualidade da educação que os estudantes recebem² (GARCíA, 1989, p. 30, tradução nossa).

Compartilhamos a definição de formação de professores a partir de García (1989) porque comungamos com sua concepção. A ideia de campo de produção de conhecimento e pesquisa ajuda a situar a necessidade de incluir o professor no processo de construção das mudanças no ensino, compreendendo-o com agente de transformação de realidades.

No tocante à formação inicial, García (1989) assegura que ela corresponde "a fase de preparação formal em uma instituição específica de formação de professores em que o futuro professor adquire conhecimentos pedagógicos e de disciplinas acadêmicas, assim como realiza as práticas de ensino3" (GARCÍA, 1989, p. 29, tradução nossa). Dessa forma, a formação do professor é compreendida como um processo no qual o aluno-mestre ou o professor em serviço é instigado a aprender o ofício da profissão docente, apenas para o primeiro caso, ou a ampliar os seus conhecimentos através do intercâmbio que começa com a formação inicial no curso de licenciatura com o aluno-mestre e, não se trata de uma exclusividade dele, visto que a formação continuada ou permanente é uma exigência para os professores em todos os níveis de ensino e vai da Educação Básica (EB) ao Ensino Superior.

Nesse sentido, García (1995) estabelece oito princípios que devem nortear a formação dos professores:

I) A concepção de que a formação do professor é contínua; havendo uma ligação entre a formação inicial e a em serviço. Portanto, o professor não pode sair da licenciatura com a visão de que está pronto e que não precisa mais estudar, pois esse é um pensamento equivocado da profissão docente. 2) A "necessidade de integrar a formação de professores, com os processos de mudança, inovação e desenvolvimento curricular4" (GARCÍA, 1995, p. 14, tradução nossa). A ideia de um processo formativo contínuo é subsidiária da necessidade de reaprendizagem(ens) do professor diante das transformações do contexto (social, educacional, tecnológico, etc.). Logo, o professor, enquanto agente de ensino, precisa estar atento às novas tecnologias e às inovações no ensino, além de manter-

\footnotetext{
${ }^{2}$ No original: "Formación del profesorado es el campo de conocimientos, investigación y de propuestas teóricas y prácticas [...], en experiencias de aprendizaje a través de las cuales adquierem o mejoran sus conocimientos, destrezas y disposiciones, $y$ que les permite intervener profesionalmente en ele desarrollo de su enseñanza, deu curriculum y de la escuela, con el objetivo de mejorar la calidad de la educación que reciben los alunos" (GARCíA, 1989, p. 30).

${ }^{3}$ No original: "Es la etapa de preparación formal en una institución específica de formación de profesorado, en la que el future professor adquiere conocimientos pedagógicos y de disciplinas académicas, así como realiza las prácticas de enseñanza" (GARCÍA, 1989, p. 29).

${ }^{4}$ No original: “[...] necesidad de integrar la formación del profesorado con los procesos de cambio, innovación y desarrollo curricular" (GARCÍA, 1995, p. 14).
} 
se em estado de alerta para as metamorfoses de toda ordem que podem alterar o ambiente escolar e a vida em sociedade.

3) A "necessidade de conectar os processos de formação do professor com o desenvolvimento organizacional da escola5" (GARCÍA, 1995, p. 14, tradução nossa). É necessário compreender que a qualificação do professor é algo positivo para a escola. O professor qualificado pode produzir bons resultados para a instituição escolar que aparecem materializados na aprendizagem dos alunos, na realização de projetos de ensino e na mobilização dos pares para o desenvolvimento de ações educativas. Portanto, ele [o professor qualificado] agrega valor pedagógico ao corpo docente da escola. 4) A "necessária articulação, integração entre a formação do professor sobre os conteúdos propriamente acadêmicos e disciplinares, e a formação pedagógica dos professores"" (GARCÍA, 1995, p. 14, tradução nossa). Não basta o professor saber o conteúdo de sua área de formação, é necessário que ele saiba por que e como ensiná-lo ao aluno. Portanto, a acumulação de conhecimentos específicos sobre determinado campo do saber não é suficiente para formar um bom professor. É pertinente que o docente avalie criticamente como aqueles saberes poderão transformar a vida do educando nos campos pessoal, social, profissional.

5) A necessidade de "integração teoria-prática na formação dos professores" (GARCÍA, 1995, p. I4, tradução nossa). A visão do encapsulamento da teoria como algo próprio da esfera acadêmica ignora o fato de que o conhecimento advindo da prática está umbilicalmente filiado a alguma proposição teórica. Portanto, essa distorção de que a teoria e a prática constituem polos antagônicos precisa ser urgentemente desconstruída, visto que a formação do professor numa perspectiva reflexiva apresenta uma superação do modelo de formação assentado na dicotomia teoria-prática.

6) A "necessidade de encontrar o isomorfismo entre a formação recebida pelo professor e o tipo de educação que ele posteriormente desenvolverá7" (GARCÍA, 1995, p. 15, tradução nossa). O ensino ofertado ao aluno da educação básica deve ser desenvolvido em congruência com a formação profissional do professor. $O$ educador crítico e reflexivo apresenta condições intelectuais para semear o espírito crítico nos seus alunos. Dessa forma, é estabelecido um comprometimento social com a cultura de conhecimentos construídos a partir da boa formação do professor que naturalmente desagua na formação do aluno.

\footnotetext{
${ }^{5}$ No original: "[...] necesidad de conectar los procesos de formación del profesorado con el desarrollo organizativo de la escuela" (GARCÍA, 1995, p. 14).

${ }^{6}$ No original: "[...] necesaria articulación, integración entre la formación del profesorado respect de los contenidos propiamente académicos y disciplinares y la formación pedagógica de los profesores" (GARCÍA, 1995, p. 14).

${ }^{7}$ No original: "[...] necesidad de buscar el isomorfismo entre la formación recibida por el professor y el tipo de educación que posteriormente se le pedirá que desarrolle" (GARCÍA, 1995, p. I5).
} 
7) "O princípio de individualização como elemento integrante de todo o programa de formação do professor8" (GARCÍA, 1995, p. 15, tradução nossa). Há uma necessidade de conscientização dos programas de formação de professores, dos professores formadores e do professorado em geral de que $\mathrm{o}$ ato de ensinar e aprender não acontece de forma homogênea para todos os indivíduos. Portanto, os AM precisam ser respeitados em suas individualidades no processo de assimilação dos conteúdos na formação inicial e, essa conduta profissional deve ser incorporada pelo futuro professor na sua prática no magistério. É necessário que os professores formadores "conheçam as características pessoais, cognitivas, contextuais, relacionais" de cada acadêmico ou "grupo de professores para o desenvolvimento de suas próprias capacidades e potencialidades"” (GARCÍA, 1995, p. 15, tradução nossa).

8) “É necessário adotar uma perspectiva que enfatize a importância da investigação e desenvolvimento do conhecimento a partir do trabalho e reflexão dos próprios professores 10" (GARCíA, 1995, p. 16, tradução nossa). O caminho para alcançar a autonomia e a transformação pedagógica do professor é iniciado a partir da reflexão crítica sobre a sua própria prática. Os questionamentos suscitados numa autoavaliação da ação docente abrem espaço para a discussão sobre o papel da teoria na prática pedagógica do professor e, sobre como essa prática transformada, reconstruída, experienciada e rediscutida alimenta um novo pensamento teórico.

O sentido que atribuímos à formação docente pelo viés da reflexividade está inserido dentro dos princípios desenvolvidos por García (1989). Através da prática de escrita reflexiva o professor desenvolve o hábito de escrever para si, numa tomada de consciência de sua existência enquanto profissional do ensino inserido numa realidade complexa e contextualizada (a sala de aula, a escola e a sociedade). Como uma espécie de alter ego, ele cria uma representação do seu mundo, permitindo-se lograr a sua transformação para a melhoria do seu trabalho pedagógico. Com isso, enfatizamos a escrita de DC e de RES como eventos de escrita sustentáveis para o letramento do professor, sendo instrumentos que potencializam o desenvolvimento da reflexão sobre a prática docente.

$\mathrm{Na}$ figura I, retomamos os questionamentos que estabelecemos, anteriormente, no $8^{\circ}$ princípio, num diálogo com o pensamento de García (1995), para explicar o ponto de partida da formação do pensamento crítico do professor sobre a sua prática docente. Para isso, recorremos a

\footnotetext{
${ }^{8}$ No original: "[...] principio de la individualización como element integrante de todo programa de formación de profesorado" (GARCÍA, 1995, p. 15).

${ }^{9}$ No original: "[...] aprender a enseñar no debe ser un proceso homogéneo para todos los sujetos, sino que será necesario conocer las características personalies, cognitivas, contextuales, relacionales etc. de cada professor o grupo de profesores para desarrollar sus propias capacidades y potencialidades" (GARCÍA, 1995, p. 15).

${ }^{10}$ No original: "Es necesario adopter una perspectiva que destaque la importância de la indagación y el desarrollo del conocimiento a partir del trabajo y reflexión por los propios profesores" (GARCÍA, 1995, p. 16).
} 
Smyth (1991), que propõe quatro indagações para a reflexão do professor, são elas: Descrição: O que eu faço?; Inspiração: Qual é o sentido do ensino que eu transmito?; Confrontação: Como me tornei assim?; Reconstrução: Como poderia fazer as coisas de forma diferente?

Smyth (199I) criou um esquema para demonstrar o ciclo de quatro fases que denotam os tipos de reflexão realizados pelos professores. Apresentamos na figura I uma reconstrução do processo em que o professor analisa o seu fazer pedagógico. A figura I é uma adaptação do fluxo das etapas de reflexão formuladas por Smyth (1991), a partir das quatro categorias por elencadas pelo autor. De acordo com a proposta desse teórico, o elemento desencadeador da reflexão do professor é a escrita reflexiva a partir da composição de DC. Compreendemos que a escrita reflexiva pode ser iniciada com o DC, mas é no RES que ela é aprofundada.

Figura I - Processo de reflexão crítica da prática de ensino do professor

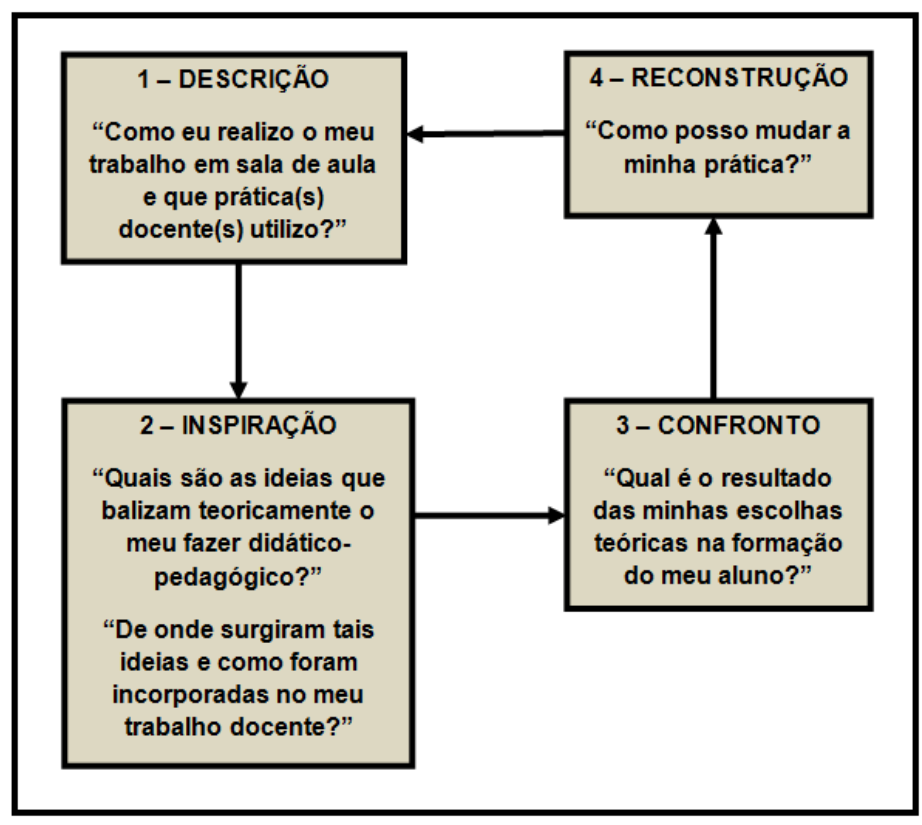

Fonte: Adaptação de Smyth (1991, p. 280).

A DESCRIÇÃO decorre do exame que o professor faz sobre as suas práticas pedagógicas a partir de uma análise pormenorizada das atividades realizadas ao longo de um período e registradas em anotações próprias, em DC. Segundo Smyth (1991), "a ideia de usar um diário [...] como uma forma de registrar experiências que poderiam ser posteriormente analisadas e partilhadas I" (SMYTH, I99I, p. 279, tradução nossa), o impressionou. Para ele, a expressão narrativa do diário abarcava no texto escrito os principais elementos que caracterizavam a situação: "O que aconteceu?", "Com quem?",

\footnotetext{
II No original: "[...] la idea de utilizer un diario como una forma de registrar experiencias que pudieran ser posteriormente analizadas y compartidas" (SMYTH, 199I, p. 279).
} 
"Quando?" e "Onde?" aconteceram os fatos. Considerando a linguagem como uma representação dos mundos (interior e exterior), a escrita do DC torna possível a recriação desses mundos materializada em texto, onde o professor tem a oportunidade ouvir a sua própria voz, o thinking aloud.

No fragmento textual $\mathrm{I}$, o estagiário escreve sobre os acontecimentos da sua $2^{\mathrm{a}}$ aula no ESC (III). A sua escrita está situada no gênero DC e apresenta na constituição do texto as tipologias textuais que respondem as produções de natureza narrativo-descritivas:

A segunda aula ocorreu dia 08/03/2012 e começamos retomando as discussões da aula anterior e explicando sobre crônica. Após a explicação entregamos uma atividade de interpretação acerca da leitura da crônica para que os alunos respondessem. Antes que começassem a responder explicamos cada questão a ser respondida, ainda assim os alunos nos solicitaram o tempo todo para que tirássemos dúvidas em relação a atividade. Durante a realização da tarefa verificamos que muitos alunos estavam com preguiça de responder e a dificuldade vinha da falta de atenção na hora da discussão. O horário da aula é um fator que contribui bastante para que os alunos fiquem desconcertados, o quinto horário tem início às I I:I 5 e é interrompido pelo horário de almoço que ocorre em qualquer parte da aula, não tem um horário específico e por isso os alunos ficam muito agitados querendo sair para o almoço. É muito complicado conseguir que eles façam a atividade de maneira adequada, a maioria faz com pressa de acabar logo ${ }^{12}$.

[R. - DC - ESC (III) - 20I2]

Na fase de DESCRIÇÃO, a experiência consiste em recontar os acontecimentos da aula para uma avaliação das ações praticadas em sala de aula. Esse exercício exige o deslocamento para a cena na qual as situações foram realizadas. Ao longo desse processo, o estagiário responde às perguntas programadas pelo texto narrativo prototípico. O texto apresenta marcadores temporais circunstanciais (“segunda aula”, “08/03/2012", “quinto horário”, “II:15”) e espaciais (“...quinto horário tem início às II:I5 e é interrompido pelo horário de almoço que ocorre em qualquer parte da aula" - ou seja, trata-se de uma escola de tempo integral, por isso os discentes realizam refeições) que revelam os elementos do contexto de situação. Há uma sequência de fatos nucleados por verbos que representam a ações desenvolvidas pelo AM durante a aula ("começamos retomando as discussões da aula anterior”, “Após a explicação entregamos uma atividade...”, “Antes que começassem a responder explicamos cada questão a ser respondida...”).

Ao longo dessas rememorações, o $A M$ refaz as suas ações no sentido de recuperar informações que possam fazê-lo examinar todo o cenário da aula. Um dado que chama a nossa atenção é o registro acerca da falta de entusiasmo dos discentes em realizar a tarefa proposta pelo professor em formação inicial, que atribui o motivo à "preguiça" e à "falta de atenção" dos alunos. O horário da aula e o fato de que a aula pode ser interrompida em qualquer momento em razão do almoço dos discentes, visto que "não tem um horário específico", causa uma situação incômoda para o professor

12 Informamos que a escrita dos DC e dos RES produzidos pelos estagiários foi preservada. Portanto, os fragmentos textuais apresentados, neste artigo, não passaram por revisão linguístico-textual. 
que fica impossibilitado de chamar a atenção dos estudantes e incapacitado para "competir" com a hora do almoço. Tal como pode ser observado, esse DC não é um texto puramente narrativo, pois nele existem trechos nos quais o AM se desprende da narração, identificado no momento em que o acadêmico discute o motivo da agitação dos alunos da EB.

Na INSPIRAÇÃO, a partir das análises de narrativas e descrições apresentadas nos DC, ou seja, após o processo de "debulhar o texto13" (YOUNG, I98I apud SMYTH, I99I p. 282) para extrair os seus significados, o professor recorre à reconstrução de sua trajetória na rememoração dos subsídios teóricos que balizaram a sua formação pedagógica.

O arcabouço teórico que fundamentou o trabalho do professor pode ser fruto da tendência ideológica dominante na sua preparação para a docência. Também pode ter sido incorporado à sua prática de ensino a partir do exercício docente quando o profissional foi inserido no sistema educacional, através da assimilação de hábitos e da construção de condutas condizentes com a filosofia educacional da escola e das instâncias majoritárias que exerceram influência sobre ele.

Nessa fase, o professor procura teorizar a sua prática para poder identificar as razões de suas ações na tentativa de justificá-las. A partir da escrita reflexiva, são expostas as teorias que podem estar sutilmente escondidas sob os comportamentos e atitudes do professor. $O$ fragmento textual 2 , mostra como o estagiário enxerga a importância do ESC na formação profissional:

Posso afirmar que o estágio é de suma importância para a formação de um acadêmico, cogito dizer isso com veemência, pois o mesmo age de forma positiva e só tem a acrescentar na melhoria do aprendizado do educando. $O$ estágio supervisionado nos proporciona desfrutar de experiências que terão relevância para nossa formação. É nesta fase tão significativa de nossa formação que passamos a articular as metodologias, os suportes teóricos, e a fala de nossos professores com a realidade existente no colégio. Assim podemos tirar nossas próprias conclusões e conectar informações para nos ajudar enquanto mente pensante, a formularmos estratégias para quando formos dar nossas aulas.

[L. - RES - ESC (II) - 20I2]

O trecho do RES mostra a INSPIRAÇÃO como fase do processo de reflexão do professor em formação inicial. O AM inicia o texto mencionando a relevância do ESC e a importância para a formação do futuro professor. Ao afirmar que "É nesta fase tão significativa de nossa formação que passamos a articular as metodologias, os suportes teóricos, e a fala de nossos professores com a realidade existente no colégio", o aluno-mestre relaciona as aprendizagens proporcionadas pelo curso formador como desencadeadoras da profissionalização.

O CONFRONTO ocorre quando o professor se depara com os resultados da sua prática materializados na aprendizagem do aluno da EB. Esse embate pode suscitar perplexidade, confusão e dúvida, pois "uma coisa é descrever e refletir sobre o ensino que oferecemos, e outra adotar uma

\footnotetext{
${ }^{13}$ A expressão "desgranar el texto" ou "debulhar o texto" foi utilizada por Young (198I). 
posição que nos faz questionar o mundo confortável que conhecemos e no qual vivemos; esta é uma tarefa muito mais difícil 14" (SMYTH, I99I p. 285, tradução nossa).

O trabalho é árduo, porque a maior dificuldade do professor é sair da situação cômoda na qual se encontra e situar a educação para além de sua sala de aula, incluindo-a no contexto cultural, social e político mais abrangente. A confrontação da prática amplia a cosmovisão do professor e desperta a mudança interior a partir de uma leitura crítica do trabalho docente.

$\mathrm{Na}$ análise dos DC e RES, o CONFRONTO compreende o momento no qual o AM questiona o resultado de suas escolhas teórico-metodológicas sobre a aprendizagem do aluno da EB. $\mathrm{O}$ fragmento textual 3 apresenta uma situação na qual $\circ$ acadêmico comenta $\circ$ fato de uma atividade planejada não ter surtido o efeito esperado nos discentes:

\begin{tabular}{l} 
Percebe-se que nos três exemplos dados, as análises produzidas pelos discentes foram breves, eles não se \\
aprofundaram na interpretação, apenas escreveram o que estava bem explícito nos dois sonetos. E no exemplo \\
3, a interpretação sobre o soneto "Aquela fera humana" não faz nenhum sentido, pois o aluno apenas encaixou \\
alguns versos do próprio mesmo. Diante desse quadro ficamos preocupadas com esse resultado, a princípio, \\
consideramos que nossas explicações e nosso desempenho durante as aulas não tinham surtidos efeitos \\
positivos e então, procuramos descobrir os motivos que levaram eles terem saídos tão mal nas atividades, \\
uma vez que, já tínhamos trabalhado bastante com interpretação de soneto. Depois de refletirmos sobre a \\
situação, entendemos que o resultado negativo apresentado pelos alunos em relação a análise de poesia \\
poderia ser decorrente da falta de prática deles, uma vez que, acreditamos que a turma não era habituada a \\
realizar esse tipo de atividade e assim, por ser algo novo, os alunos não compreenderam nossa proposta, \\
embora nos empenhamos muito durante as aulas para que eles pudessem se familiarizar com a interpretação \\
de poesia. \\
\hline [l. - RES - ESC (IV) - 20I3]
\end{tabular}

A atividade em questão consistia na análise de três textos poéticos. O AM ficou decepcionado, pois acreditava que os alunos da EB conseguiriam realizar a interpretação dos poemas sugeridos na aula. Em dois casos, nas leituras dos sonetos, não houve um aprofundamento das análises e os alunos da EB restringiram as suas interpretações ao "que estava bem explícito" nos textos. No terceiro caso, o aluno da EB produziu um texto sem sentido com versos do próprio poema.

Frente a esse fato, o AM confronta a não aprendizagem dos discentes com as suas realizações em sala de aula. Esse resultado negativo leva-o a uma reflexão sobre as suas práticas: "Depois de refletirmos sobre a situação, entendemos que o resultado negativo apresentado pelos alunos em relação à análise de poesia poderia ser decorrente da falta de prática deles (...)”.

A sua conclusão sobre o fato é de que "os alunos não compreenderam nossa proposta, embora nos empenhamos muito durante as aulas para que eles pudessem se familiarizar com a interpretação

\footnotetext{
${ }^{14}$ No original: "[...] una cosa es describer y reflexionar sobre la enseñanza que impartimos, y outra adopter nosotros mismos una posición que nos haga cuestionar el cómodo mundo que conocemos y en el que vivimos; esta es una tarea mucho más difícil” (SMYTH, 199I, p. 285).
} 
de poesia". Após ponderar o seu próprio empenho no planejamento e na realização das aulas, o alunomestre considera que a falta de familiaridade dos alunos da EB com o texto literário dificultou a sua apropriação com o gênero trabalhado na aula.

O fragmento textual 4 apresenta um recorte de um RES produzido durante o ESC (IV). Nele, o aluno-mestre comenta uma atividade de produção textual realizada após a leitura e a discussão do texto da Carta de Pero Vaz de Caminha:

(...) solicitamos aos discentes que produzissem uma carta dirigida ao prefeito de $* * * *$, a qual seria diferente da Carta de Caminha que exaltava as riquezas do Brasil, pois em suas produções eles apontariam os problemas sociais de sua cidade identificados pelos mesmos. (...) Tivemos resultados excelentes com as produções dos alunos, pois todos se empenharam e apontaram os principais problemas que eles achavam que prejudicava nossa cidade, e ainda, pediram ao prefeito que procurasse solucioná-los. (...) podemos observar os alunos apontaram os problemas sociais que mais prejudicam nossa cidade: o descaso com a saúde e com a educação, o aumento da violência, a precariedade do transporte público, ruas sem pavimentação, entre outros. (...) Consideramos essa atividade de escrita da carta ao prefeito muito significativa, porque através dela o aluno foi conduzido a voltar seu olhar para os acontecimentos que fazem parte de seu meio social, e de certa forma, levando o mesmo a se posicionar diante dessa realidade de descaso do poder público. Assim, faz-se necessário que a escola possibilite ao aluno a experimentar atividades que provoque nele interesse tanto pela sua vivência escolar como para os acontecimentos do seu cotidiano, para que possa agir sobre o mundo que vive.

[L. - RES - ESC (IV) - 20I3]

A atividade de produção textual solicitava que o aluno da EB redigisse uma carta dirigida ao prefeito da cidade, notificando o comandante do poder executivo sobre os problemas que as pessoas enfrentam no seu dia a dia na comunidade. Diferentemente da Carta de Caminha, "que exaltava as riquezas do Brasil”, o texto a ser produzido deveria refletir os anseios da população visando à melhoria das condições de vida na cidade.

Sobre essa atividade, o acadêmico afirma que os resultados foram "excelentes (...), pois todos se empenharam e apontaram os principais problemas que eles achavam que prejudicava nossa cidade, e ainda, pediram ao prefeito que procurasse solucioná-los”. Nesse contexto, além de o aluno da EB escrever sobre um dado da realidade dele, ele também tinha um leitor potencial para quem a carta estava endereçada, o prefeito.

O conhecimento desse contexto permitiu ao aluno da EB elaborar textos em que ele demonstra ter notório saber sobre o qual o aluno-mestre cita: "o descaso com a saúde e com a educação, o aumento da violência, a precariedade do transporte público, ruas sem pavimentação, entre outros". Os discentes tinham familiaridade com o gênero textual carta. Eles sabiam o que escrever, assim como para quem escrever e tinham informações suficientes sobre o assunto a ser discutido nos textos.

Ao confrontar o resultado das produções textuais dos alunos da EB com a escolha teóricometodológica aplicada, o AM revela satisfação ao alcançar os seus objetivos com a aula. Ao afirmar que 
cabe à escola proporcionar aos discentes a realização de atividades que "possibilite ao aluno a experimentar atividades que provoque nele interesse tanto pela sua vivência escolar como para os acontecimentos do seu cotidiano, para que possa agir sobre o mundo que vive", o aluno-mestre, como professor, toma para si essa responsabilidade. Através dessa atividade, ele fornece meios para que os alunos da EB desenvolvam as suas potencialidades na construção de textos que refletem suas vivências.

Na RECONSTRUÇÃO, o professor, ciente da necessidade de mudança de suas práticas, a partir da avaliação realizada nas etapas anteriores, anseia pelo recomeço e busca capacitar-se na tentativa de desenvolver um trabalho de melhor qualidade. Através da reflexão crítica sobre as implicações histórico-sociais e a compreensão da importância dos fatores contextuais para os resultados do ensino, o professor consegue problematizar as questões que interferem na sua prática educacional como indutores negativos do seu trabalho.

Seria por demasiado precipitado considerar que todo esse processo de autocrítica e autoconhecimento fosse uma tarefa fácil, pois a transformação de ações didáticas e concepções de ensino incutidas, muitas vezes estão enraizadas na personalidade do profissional. A reconstrução de uma prática pedagógica demanda de uma redefinição de posturas, atitudes, comportamentos, além da reavaliação dos procedimentos didáticos empregados, replanejamento de estratégias de ensino e avaliação.

No fragmento textual 5, o AM comenta a sua trajetória ao longo das aulas ministradas na escola campo de estágio durante o ESC (IV):

(...) nossa última fase do processo de formação foi exaustiva e desgastante, tentamos trabalhar da melhor forma possível buscando alcançar sucesso em nossas aulas, no entanto ao realizarmos as aulas nem tudo deu certo e nem sempre conseguimos correlacionar teoria e prática, apesar de todo nosso planejamento e preparação. É lógico que sabemos que falta experiência e uma maior preparação, talvez com o tempo, quando efetivamente estivermos atuando em uma turma consigamos obter o tão almejado sucesso no ensino de língua materna.

[A. C. - RES - ESC (IV) - 20I3]

O sentido de RECONSTRUÇÃO no discurso do acadêmico aparece na sua capacidade de reconhecer que aquilo que não deu certo precisa ser repensado e replanejado. Segundo o AM, a etapa final dos ESC foi "exaustiva e desgastante". Houve a tentativa de fazer o melhor, mesmo errando. Esse texto mostra uma disponibilidade em aprender.

Errar é uma etapa do processo que leva o sujeito a aprender determinada tarefa. Portanto, o "erro", não significa algo ruim, pois implica em aprendizagem. Aprender também envolve reflexão sobre algo que deu errado. Esse processo de aprendizagem é cíclico e é desencadeado pela reflexão sobre uma ação que conduz a uma nova reflexão e uma nova ação e assim sucessivamente. 
De acordo com o texto, o AM tem consciência de seu papel e de suas limitações enquanto professor em formação inicial. Outro dado, também importante, diz respeito à sua compreensão de que a construção de uma prática pedagógica acontece dentro de um longo processo de vivências em situações de ensino.

Mesmo considerando esse fato, o ESC marca o início de uma trajetória na docência do futuro professor. No recorte, "quando efetivamente estivermos atuando em uma turma consigamos obter o tão almejado sucesso no ensino de língua materna" existe um desejo contido de atuar na educação, de pôr à prova os conhecimentos adquiridos, de experienciar de forma efetiva o dia a dia de uma escola, de uma sala de aula.

O significado de ser reflexivo não se resume em enxergar a si próprio na análise de suas ações, mas consiste em realizar o movimento de olhar para dentro e para fora da sua realidade. A reflexão para além da escola torna-se possível à medida que o professor percebe a inexistência de uma educação apolítica e a-histórica ou de um ensino desprovido de teorização. Nas palavras de Freire (1996), enquanto atividade humana, "a educação é gnosiológica, é diretiva, por isso política, é artista e moral, serve-se de meios, de técnicas, envolve frustrações, medos, desejos” (FREIRE, 1996, p. 70). Para concluir, o autor afirma que a educação "exige de mim, como professor, uma competência geral, um saber de sua natureza e saberes especiais, ligados à minha atividade docente” (FREIRE, 1996, p. 70).

Portanto, o professor não é um sujeito dito neutro, sua prática educativa e o seu trabalho são essencialmente humanos, porque ele lida no dia a dia, além dos seus próprios dilemas, com as aspirações de seus alunos. $O$ emprego do termo gnosiológico, tal como explica o próprio Freire (1996), advém desse envolvimento de sujeitos, "um que, ensinando, aprende, outro que, aprendendo, ensina" (FREIRE, 1996, p. 69). Nessa relação, o professor deve manter a porta permanentemente aberta com a disponibilidade de ir ao encontro do outro e do novo, para a possibilidade de mudança de práticas e (re)avaliação de ideias preconcebidas.

A reflexão sobre o ensino é uma atividade mental orientada pela análise de determinada situação, definida no tempo e no espaço que envolve a formulação de um pensamento planejado. Como elemento substantivo da prática do professor, "a reflexão é a ligação entre a ação passada e as ações futuras através do fornecimento de informações sobre as operações e resultados 15" (YINGER, 1988, p. 14, tradução nossa).

O exercício da reflexão na prática profissional do professor pode ser representado por momentos de autoavaliação, nos quais o docente imerge numa autorreflexão na busca de solução para

\footnotetext{
15 No original: "Reflection is the process by which success of planning and action are tracked and assessed. Reflection is the link between past action and future action by supplying information about operations and outcomes" (YINGER, 1988, p. 14).
} 
seus problemas no âmbito do ensino. Essa atividade de refletir sobre as ações planejadas ou não planejadas, conduz o professor a avaliar e reavaliar sua forma de ensinar e de interagir com os alunos.

Essa reflexão pode envolver os registros escritos, a elaboração de textos de campo (diários) que traduzem as emoções e os pontos de vista originários da interação do professor com os seus alunos e com a realidade escolar. É esse o tipo de reflexão que o AM realiza na composição de suas produções textuais (DC e RES).

Perrenoud (2002) afirma que não existe ação complexa sem reflexão. Segundo o autor, a reflexão na ação "consiste em se perguntar o que está acontecendo ou o que vai acontecer, o que podemos fazer, o que devemos fazer, qual é a melhor tática, que desvios e precauções temos de tomar, que riscos corremos etc." (PERRENOUD, 2002, p. 30-31). Trata-se da "reflexão acerca da situação, dos objetivos, dos meios, do lugar, das operações envolvidas, dos resultados provisórios, da evolução do previsível do sistema de ação" (PERRENOUD, 2002, p. 30). No caso da reflexão sobre a ação, é a própria ação do professor que constitui o objeto de sua reflexão. Dessa forma, o professor se debruça sobre a análise de suas ações didático-pedagógicas, com o objetivo de ressignificar a sua prática no intuito de "compreender, aprender e integrar o que aconteceu", de modo a explicá-las e criticá-las.

Para Perrenoud (2002, p. 31), "a reflexão não se limita a uma evocação, mas passa por uma crítica, por uma análise, por uma relação com regras, teorias outras ações, imaginadas ou realizadas em uma situação análoga”. Portanto, a prática reflexiva envolve a incorporação pelo professor de uma atitude investigativa em que as suas ações se tornam objetos de análise. Para que isso ocorra, é necessário ao professorado a construção interior de uma postura crítica sobre as dimensões do processo de ensino e aprendizagem, assim como sobre as práticas educacionais individuais enraizadas no sistema gerencial e pedagógico das escolas.

A reflexão orientada apenas sobre o exercício docente do professor pode fomentar uma visão “individualista” (ZEICHNER, 2008) ou "narcisista” (BARREIRO; GEBRAN, 2006), portanto, restritiva, por não englobar o contexto no qual se manifestam as relações assimétricas estabelecidas por governos e suas políticas educativas, comunidades e escolas, escolas e famílias. Daí a razão pela qual Zeichner (2008), defende que haja uma expansão do pensamento crítico do professor para além do muro da escola, onde os fatores socioculturais, políticos e econômicos provocam uma entropia no sistema macroestrutural dinâmico que é refletido na sala de aula.

Assim, as dimensões do trabalho do professor que se encontram pautadas em reinvindicações na estruturação da educação têm como finalidade a formação de cidadãos reflexivos, aptos a exercer funções sociais e a exigir os seus direitos ante a sociedade. Por isso, o ato de ensinar e aprender desencadeia consequências próprias da ação educativa e o professor no exercício de sua profissão precisa ter a consciência do impacto das suas decisões e o efeito dessas sobre a vida dos estudantes. 
Guiado pelo bojo de atitudes necessárias ao professor reflexivo (Mente Aberta, Responsabilidade, Sinceridade), desenhadas por Dewey (1933), Zeichner (2008) destaca as consequências pessoais, acadêmicas, políticas e sociais que pesam sobre as ações reflexivas dos professores na prática docente:

Os professores precisam saber o conteúdo acadêmico que são responsáveis por ensinar e como transformá-lo, a fim de conectá-lo com aquilo que os estudantes já sabem para o desenvolvimento de uma compreensão mais elaborada. Precisam saber como aprender sobre seus estudantes - o que eles sabem e podem fazer, e os recursos culturais que eles trazem para a sala de aula. Os professores também precisam saber como explicar conceitos complexos, conduzir discussões, como avaliar a aprendizagem discente, conduzir uma sala de aula e muitas outras coisas. A ligação da reflexão docente com a luta por justiça social significa que, além de certificar-se que os professores têm o conhecimento de conteúdo e o conhecimento pedagógico que eles precisam para ensinar, de uma maneira que desenvolva a compreensão dos estudantes (rejeitando um modelo transmissivo de ensino que meramente promove a memorização), precisamos nos certificar que os professores sabem como tomar decisões, no dia-a-dia, que não limitem as chances de vida de seus alunos; que eles tomem decisões com uma consciência maior das possíveis consequências políticas que as diferentes escolhas podem ter (ZEICHNER, 2008, p. 546).

Zeichner (1998) lembra que a ação reflexiva vai além da resolução de problemas racionais e lógicos, pois, segundo o autor, ela envolve "intuição, emoção e paixão" e não compreende "um conjunto de técnicas para o uso dos professores 16" (ZEICHNER, 1998, p. 3, tradução nossa). professor reflexivo não se encontra alheio aos impactos sociais e emocionais, evidenciados nas relações interpessoais estabelecidas com os alunos que são provocados por suas ações no dia a dia das interações em sala de aula (consequência pessoal).

Dentro do rol das responsabilidades do professor reflexivo está o compromisso com a formação acadêmica dos alunos, com a aquisição dos conteúdos de maneira não transmissiva, conectando-os criticamente com a realidade e com as aprendizagens anteriores dos discentes (consequência acadêmica). Também é competência do professor reflexivo desenvolver nos alunos a consciência de que a educação é um instrumento de mudança político-social e de transformação de vidas (consequência política e social).

\section{Considerações finais}

A formação reflexiva do professor, fomentada pela pesquisa na docência, gera um sistema ininterrupto de diálogos e troca de saberes entre instituições formativas de ensino e escolas com ganhos mútuos para um objetivo comum, o anseio por uma educação de qualidade. Através deste

\footnotetext{
${ }^{16}$ No original: "Reflective action is also a process that involves more than a logical, rational problem solving process. Reflection involves intuition, emotion, and passion it is not something that can be neatly packaged as some have tried to do, and taught as a set of tecniques for teachers to use" (ZEICHNER, 1998, p. 3).
} 
artigo, procuramos discutir o processo de construção da escrita reflexiva, na produção de DC e RES, sobre as práticas docentes evidenciadas no âmbito do estágio supervisionado.

Ao longo deste texto, apresentamos a análise de exemplares textuais extraídos de DC e RES, produzidos por professores em formação inicial, durante suas vivências em atividades de estágio supervisionado. Examinados à luz do quadro teórico delineado por Smyth (1991), os textos analisados concretizam as etapas do processo de reflexão crítica da prática de ensino do professor (descrição inspiração - confronto - reconstrução). Tais etapas podem ser evidenciadas nos textos a partir da identificação de movimentos discursivos que revelam o aprendizado da profissão do professor dentro de um processo de formação mediado pelo registro do texto escrito.

Essa incursão teórico-analítica aponta que os acadêmicos assumem uma postura reflexiva à medida que registram percepções que integram o conjunto de informações que contextualizam o contato com a escola, com os professores, com os alunos da Educação Básica e com o ambiente de ensino na universidade. Consideramos que o cruzamento de contextos (o aprender a ensinar e o ensinar aprendendo) resulta numa fusão de mundos que pode originar uma conjunção ou disjunção dos saberes apreendidos no campo da formação profissional do professor.

\section{Referências}

BARREIRO, I. M. F.; GEBRAN, R. A. Prática de ensino e estágio supervisionado na formação de professores. São Paulo: Avercamp, 2006.

BAZERMAN, C. Gêneros textuais, tipificação e interação. 4. ed. São Paulo: Cortez, 20 II.

BORTONI-RICARDO, S. M. O professor pesquisador: introdução à pesquisa qualitativa. São Paulo: Parábola Editorial, 2008.

DEWEY, J. How we think: a restatement of the relations of reflective thinking to the educative process. 2. ed. Boston: DC Heath, 1933.

FIAD, R. S.; SILVA, L. L. M. Escrita na formação docente: relatos de estágio. Acta Scientiarum Language and Culture, Maringá, v. 3I, n. 2, p. I23-131, 2009. Disponível em:

http://periodicos.uem.br/ojs/index.php/ActaSciLangCult/article/view/3600. Acesso em: I4 maio 2019.

FLICK, U. Introdução à pesquisa qualitativa. 3. ed. Porto Alegre: Artmed, 2009.

FREIRE, P. Pedagogia da autonomia: saberes necessários à prática educativa. 39. ed. São Paulo: Paz e Terra, 1996.

GARCÍA, C. M. Formación del profesorado para el cambio educativo. Barcelona: EUB, 1995.

GARCÍA, C. M. Introducción a la formación del profesorado: teoría y métodos. Sevilla:

Servicio de Publicaciones de la Universidad, 1989.

PERRENOUD, P. A prática reflexiva no ofício de professor: profissionalização e razão 
pedagógica. Porto Alegre: Artmed, 2002.

SIGNORINI, I. (Org.). Gêneros catalizadores: letramento e formação do professor. São Paulo: Parábola Editorial, 2006.

SILVA, W. R. Escrita do gênero relatório de estágio supervisionado na formação inicial do professor brasileiro. Revista Brasileira de Linguística Aplicada (RBLA), Belo Horizonte, v. I3, p. I7I 195, 2013. Disponível em: https://www.scielo.br/pdf/rbla/20I2nahead/aopl7/2. Acesso em: 10 fev. 2018.

SILVA, W. R.; FAJARDO-TURBIN, A. E. (Org.). Como fazer relatórios de estágio supervisionado: formação de professores nas licenciaturas. Brasília: Liber Livro, 2012.

SMYTH, J. Una pedagogía crítica de la práctica en el aula. Revista de Educación, n. 294, p. 275-300, 1991. Disponível em: http://www.educacionyfp.gob.es/revista-de-educacion/numeros-revistaeducacion/numeros-anteriores/1991/re294/re294-I4.html. Acesso em: I5 ago. 2019.

YINGER, R. J. The intelligence of practice. In: WAXMAN, H. C. et al. (Org.). Images of Reflection in Teacher Education. Association of Teacher Educators Reston, 1988.

ZEICHNER, K. M. Reflective Teaching. Chulalongkorn, Thailand, v. 4, n. 2, p. I-9, 1998.

ZEICHNER, K. M. Uma análise crítica sobre a "reflexão" como conceito estruturante na formação docente. Educação \& Sociedade. Campinas, v. 29, n. 103, p. 535-554, maio/ago. 2008. Disponível em: https://www.scielo.br/pdf/es/v29n 103/I2.pdf. Acesso em 18 set 2019.

Recebido em: 03 de junho de 2020.

Versão corrigida recebida em: 04 de junho de 202I.

Aceito em: 23 de junho de 2021 .

Publicado online em: 04 de fevereiro de 202I. 